\title{
Condiciones culturales y recepción del psicoanálisis en Córdoba, Argentina $(1915-1942)^{1}$
}

\section{Cultural conditions and reception of psychoanalysis in Córdoba, Argentina (1915-1942)}

\author{
Fernando José Ferrari \\ Consejo Nacional de Investigaciones Científicas y Técnicas (CONICET)
}

(Rec: abril 2014 - Acep: junio 2014)

\begin{abstract}
Resumen
En este trabajo intentamos delimitar las principales condiciones de recepción de la teoría de Freud en Córdoba. A su vez, mostramos los puntos distintivos que este proceso tuvo y establecemos las diferencias que se dieron con la recepción de la teoría freudiana en Buenos Aires. Estas particularidades culturales sirven de marco para las ideas del médico vienés en Argentina, siendo parte de una tensión fundamental y constitutiva de la historia del país. A partir de lo anterior, nuestro trabajo introduce, como eje interpretativo, a la dicotomía interior-puerto, que da cuenta de tensiones políticas y culturales. Se exponen como principales ejes de la recepción en Córdoba: 1) el rechazo y discusión del positivismo, 2) la existencia de una cultura de raigambre religioso y conservador, y 3) la influencia de la cultura hispánica, en especial la filosofía vitalista española implantada por Ortega y Gasset y Eugenio D’Ors.
\end{abstract}

Palabras clave: historia, recepción, psicoanálisis, Córdoba.

\begin{abstract}
In the present review we aim to outline the main conditions for the reception of Freud's theory in Cordoba, Argentine. We will try to display the distinctive points that this process had and establish the differences occurred with the reception of Freud in the city of Buenos Aires. These cultural characteristics that frame the reception of the ideas of the Viennese physician are part of a fundamental and constitutive tension in Argen0tinian's history. That is why our work introduces, as an interpretative axis, the interior-harbor dichotomy that accounts for such political and cultural tensions. We will expose the principal axes of the reception in Cordoba: 1) rejection and discussion of positivism 2) the existence of a traditional culture and conservative religious thought and 3) influence of Hispanic culture, and especially the Spanish vitalist philosophy implemented by Ortega y Gasset and Eugenio D'Ors.
\end{abstract}

Keywords: history, reception, psychoanalysis, Cordoba.

\footnotetext{
1 Esta investigación se encuentra asociada al proyecto "Historia del psicoanálisis, la psicología y la psiquiatría en Córdoba: la incidencia del psicoanálisis lacaniano en la constitución del perfil del psicólogo (1966-1976)" financiado por la Secretaria de Ciencia y Técnica (SeCyT) $\mathrm{N}^{\circ} 1565 / 2014$, de la Uiversidad Nacional de Córdova.

2 Correspondencia a: Fernando José Ferrari, Maipú 5089 B, Córdoba, Argentina. Correo electrónico: ferrarijfernando@gmail.com.
} 


\section{Introducción}

En el presente artículo nos centraremos en la recepción del psicoanálisis en Córdoba (Argentina), e intentaremos mostrar el modo en que la idiosincrasia local enmarcó el modo de recepción de las teorías de Sigmund Freud en el período previo a la institucionalización del psicoanálisis (1915-1942). Para ello expondré las primeras apreciaciones de la obra freudiana, publicaciones distribuidas en tres vertientes. $\mathrm{La}$ primera realizada por la psiquiatría progresista, afectada por un naturalismo médico y las ideas de Francia. La segunda, una serie de lectores de Freud en diversas disciplinas, filosofía, literatura y medicina, que fueron afectados por las filosofías vitalistas españolas que tanto impacto tuvieron en la reacción anti-positivista de mediados de la década del diez. La última vertiente de recepción, fue representada por un rotundo rechazo por parte de la intelectualidad religiosa, cuya injerencia política alcanzó a casi todas los planos institucionales. Las dos primeras líneas interpretativas compartieron (aunque con diferencias doctrinarias), el fenómeno de la Reforma Universitaria de 1918 en Córdoba.

Las condiciones culturales de la ciudad, establecieron un marco de posibilidades para leer la obra de Freud. A continuación, presentaré las tres aristas que delimitarán esas condiciones. En primer lugar, tanto Plotkin (2003), Vezzetti (1996) como Dagfal (2009), plantean que la cultura francesa, el positivismo y la inmigración tuvieron un fuerte impacto en la conformación cultural de la Argentina. Córdoba no sería ajena a la influencia de estos tres vectores que trazaron los surcos en donde emerge el Estado Nacional y sus dispositivos de salud y educación modernos. Sin embargo, Córdoba se vio afectada de un modo particular en virtud de su pesada tradición hispánica y de las disputas por la concentración del poder político y económico que se dieron entre las provincias luego de la Revolución de Mayo de 1810. Tales disputas, terminarían por consolidar un federalismo "imperfecto" (Dagfal, 2009) en el que Buenos Aires se tornó en el centro político y económico del país, todo ello en un proceso que no ahorró guerras civiles y querellas políticas de largo aliento. En este sentido, el positivismo en Córdoba no tuvo el auge que presentó en Buenos Aires. Una segunda condición, corresponde a la presencia de la intelectualidad religiosa en la cultura cordobesa. Finalmente, la presencia de los intelectuales españoles a partir de finales de la década del ' 10 , tendrá un particular impacto.

Este trabajo busca cuestionar resultados de investigaciones previas sobre la historia del psicoanálisis en
Argentina, al introducir un análisis de las condiciones culturales e intelectuales que contextualizan la recepción de las ideas de Freud en Córdoba, Argentina. A grandes rasgos, las investigaciones en historia del psicoanálisis en Argentina (Plotkin, 2003; Vezzetti, 1996; García, 1978; Dagfal, 2009) suelen generalizar los resultados que se obtuvieron en Buenos Aires al resto del país. Esta generalización deja de lado las particularidades culturales dentro de Argentina, cuya extensa geografía ha generado microclimas culturales con tradiciones diferentes a las que se expresaron en la capital del país.

En lo siguiente se expone nuestro compromiso teórico metodológico con una historia crítica de la psicología, marco que permite el desarrollo de una historia intelectual y un estudio de recepción de las ideas psicológicas. Luego, presentaremos nuestros resultados y posteriormente la discusión de los mismos.

\section{Marco teórico y metodológico}

Este trabajo ha sido desarrollado a partir del compromiso con una historia crítica de la psicología, tal como la presentan Kurt Danziger (2010) y Brock, Louw y Van Hoorn (2005). Este tipo de estudios críticos, han buscado interrogar las historias legitimadoras del conocimiento científico en relación con su inscripción disciplinar e institucional, de modo que introducen una dimensión propiamente social al momento de explicar la existencia de productos epistémicos. Danziger se interesa por la dinámica de la generación y difusión de los conocimientos psicológicos planteando, a partir de la noción de indigenización, que los conceptos y prácticas psicológicas se ven asimilados en el proceso de importación. Según Danziger, se hace necesario abordar la historia de la psicología en términos policéntricos para indagar la "migración transcultural de categorías psicológicas" (Danziger, 1994).

Klappenbach (2014) delimita ocho fases metodológicas que una historia crítica debe cumplir. La primera implica la delimitación o construcción de un objeto de estudio acotado. En nuestro caso, el objeto de estudio es el proceso de recepción de las ideas de Freud en Córdoba. La segunda fase, consiste en el establecimiento de las preguntas e hipótesis de trabajo. En nuestro caso la pregunta ¿Cuáles fueron las condiciones de recepción de las ideas de Freud en Córdoba en el período de 1915 a 1942? La tercera fase, ligada íntimamente a la anterior, es la del establecimiento del estado del arte, el cual se verá reflejado en el decurso del artículo 
en una exposición de las principales investigaciones del área, a partir de las cuales podemos cotejar la originalidad de nuestra investigación. La cuarta fase, es la selección del diseño metodológico propiamente dicho. Los diseños de investigaciones en historia de la psicología "no siempre encajan en las clasificaciones de investigaciones psicológicas, porque se trata de estudios de naturaleza histórica y no psicológica." (Klappenbach, 2014, p. 6). No obstante, nuestro estudio se podría enmarcar en variaciones de estudios ex post facto restrospectivos, de acuerdo a la clasificación de Montero y León (2005), mientras que consideramos nuestra aproximación metodológica como cualitativa. Esta última se desprende de nuestro compromiso teórico con una historia intelectual que "aunque inscribe su labor dentro de la historiografía, su ubicación está en el límite de ese territorio, y a veces (por los materiales que trabaja, por el modo en que los interroga o por las facetas que explora en ellos) cruza el límite y se mezcla con otras disciplinas" (Altamirano, 2005, p. 10). Esto quiere decir que la singularidad de su abordaje radica menos en sus métodos que en su perspectiva de lectura, que construye sus objetos en una constelación de relaciones entre discursos, representaciones, prácticas e instituciones buscando una articulación entre la historia social y cultural, y la biografía individual, entre la historia política y los debates disciplinares. Me pregunto por el modo en que las ideas de Freud, fueron aplicadas y transformadas en función de un horizonte de problemáticas locales. Este problema es abordado por los estudios de recepción de las ideas. En este sentido, adhiero a la propuesta de una estética de la recepción de las ideas psicológicas que presenta Alejandro Dagfal (2004), a partir de los desarrollos de Jauss $(1981 ; 1990)$ e Iser (1972). Un estudio de recepción de las ideas contempla las lecturas y adaptaciones que se realizan en función de un contexto de recepción que modifica activamente las ideas recibidas.

La quinta fase metodológica, implica la selección de fuentes y/o de los testimonios claves de donde emergerán los datos empíricos de la investigación. La sexta fase, corresponde a la recolección o construcción de datos previa a la selección de fuentes primarias. La selección de estas fuentes estuvo orientada por la necesaria presencia de referencias al psicoanálisis en el período propuesto. El relevamiento bibliográfico se torna fundamental aquí puesto que la recolección de datos es "... el resultado de un proceso de construcción intelectual y social" (Klappenbach, 2014, p. 7) y no un simple acto de compilación documental. Finalmente la séptima y octava fases metodológicas a las que respondió este trabajo, se realizan paralelamente a las dos instancias previas. Estas son el análisis e interpretación de los datos, cuyos principios hermenéuticos están guiados por los compromisos teóricos delimitados en el párrafo anterior y que implica un análisis comparativo de las condiciones culturales de recepción de las ideas de Freud, entre Buenos Aires y Córdoba. La última fase, la presentación del análisis de los datos, coincide con lo que Ricoeur (2004) denomina fase representativa o literaria, que implica la reconstrucción histórica plasmada en una narrativa orientada por el problema de investigación y la valoración de las fuentes primarias. Esto es lo que el lector podrá encontrar en el desarrollo de los resultados, que se presentan en lo que sigue.

\section{Resultados}

\section{Condiciones de posibilidad y recepción de la obra de Freud en Córdoba}

Sobre la primera condición, la recepción del positivismo, afirmamos que su discusión y acogida tuvo un particular desarrollo en Córdoba. El tradicionalismo católico, que tiene una expresión histórica en la ciudad, generó una recepción crítica del positivismo. Incluso, pese a la gran influencia de intelectuales como José Ingenieros, el positivismo encontró un fuerte rechazo en sus diversos compromisos. En particular, la noción de determinismo entró en conflicto con la de libre albedrío, fundamento de la fe religiosa. Tal como menciona Schermann:

En el claustro universitario local, la filosofía oficial se encontraba totalmente alejada de las corrientes predominantes en psicología a nivel nacional y estancada su producción aún en su propio marco de rechazo al liberalismo político o al positivismo filosófico porteño. (Schermann 2009, p. 150)

Moyano Gacitúa en su Curso de ciencia criminal, (1899) aceptaba los postulados de la ciencia positiva de un modo crítico, descartando el determinismo y la idea del Uomo Delinquente de Lombroso, al tiempo que opinaba que el terreno de la moral debía ser abordado con una formación religiosa. Esta opinión se reproduce en varias tesis de derecho: "....rechazo y rechazaré siempre, el que la trasmisión hereditaria sea fatal y necesaria y con más razón de que el vicio y la virtud, los sentimientos, todo lo noble y grande se trasmita, 
cual pueda trasmitirse la predisposición para la tisis, u otra enfermedad cualquiera" (Nores, 1904; p. 26).

La segunda condición de la recepción del psicoanálisis, relacionada a la valoración crítica del positivismo, refiere al tradicionalismo religioso cordobés. Éste último se sostuvo en todas las facetas de la política de la ciudad mediterránea. En Ferrari (2012) hemos mostrado la fuerte presencia de la cultura religiosa en el aparato sanitario cordobés. El proceso de centralización social, político y económico en la ciudad de Buenos Aires, produjo un sistema sanitario sostenido por la Nación en la "ciudad del Puerto". En las provincias, los manicomios fueron subvencionados por el gobierno provincial y en gran medida por las Sociedades de Beneficencia. Este hecho produjo que el aparato administrativo del sistema asilar reproduzca la presencia de personal religioso y retrase la modernización. A su vez esta presencia del discurso y las prácticas religiosas en el ámbito de la locura, en particular el Hospital de Alienadas, marcó una de las características de la aceptación del psicoanálisis en Córdoba. Más aún, en virtud de la presencia sistemática de médicos de orientación religiosa, como León Morra o Ariosto Licurzi, el psicoanálisis no tuvo mayor recepción en el Hospital de Alienadas, ni en la Facultad de Medicina (como veremos, exceptuando la incursión de Gregorio Bermann) ni en la Facultad de Filosofía. En esta vía, encontraremos los estudiosos opositores al freudismo: Filemón Castellanos, Cacciaviliani, Héctor Luis Torti, Nimio de Anquín, Emilio Gouirán, etc.

La tercera condición es la incidencia de la cultura española. En las ciudades del interior, y en especial Córdoba, la tradición cultural hispánica siempre tuvo un lugar destacado, sea por la vía del tradicionalismo católico como de la intelectualidad progresista. Partimos desde la idea de que la tensión que se genera entre el interior y el puerto, es importante para comprender las particularidades de la recepción del psicoanálisis. Proponemos que la disputa por la influencia de la cultura francesa o española, fue un elemento distintivo importante al momento de expresar esa tensión entre el puerto y el interior del país. Esta tensión puede verse recurrentemente representada en el reconocido texto de Sarmiento, el Facundo, donde las oposiciones y las analogías adquieren un valor simultáneamente pedagógico e interpretativo. De este modo, la oposición de base (civilización y barbarie) es desplegada en sucesivas oposiciones menores que mantienen la estructura

\footnotetext{
3 Del mismo cariz pueden consultarse: Colodrero Lazcano, Oscar (1908) Teoría de la culpa en materia penal. Y también González, 1890 , entre otros.
}

de la matriz (ciudad y campaña, siglo XIX y siglos XII y XVI, Buenos Aires y Córdoba, Europa y España), pero cada una de las partes es, a su vez, desarrollada a partir de las analogías existentes entre unos y otras: lo que hay de medieval en la cultura española, lo que hay de España en Córdoba, lo que hay en Córdoba de estancamiento y atraso, lo que hay en la barbarie de la campaña del componente cordobés, esa ciudad docta, dice Sarmiento, "que no ha tenido hasta hoy, teatro público, no conoció la ópera, no tiene aún diarios, y la imprenta es una industria que no ha podido arraigarse alli’" (Prieto, 2006, p. 123). Así, es posible decir que el lugar que ha sido destinado a Córdoba en el proyecto de Sarmiento es un indicador de una distribución espacial que dispone del poder justificando la concentración de capitales, monetarios y simbólicos, en la ciudad del puerto, lo que denota una escena conflictiva entre el interior y Buenos Aires.

El proceso de centralización que se dio en la Argentina tuvo como agente principal a Buenos Aires y en ello se presentó una reconfiguración cultural que replanteó las relaciones de poder entre Córdoba y la capital. Esta implicancia tomó un sesgo psicopatológico cuando Ramos Mejía, en La neurosis de los hombres célebres (1880), alineado desde el binomio Civilización $o$ Barbarie, declaró enfermiza cualquier implicancia política que no se sometiera a la centralidad del puerto, como menciona Vezzetti:

Por otro lado, combinada a esa imagen incoercible de la herencia racial se señala la acción de los traumas políticos y los efectos negativos de los refinamientos de la civilización. Ante todo, las conmociones políticas son agentes de la locura y obligan a plantear un alerta respecto de los efectos de una excesiva movilización y participación popular en los acontecimientos políticos: Morbus democraticus. La democracia puede ser una enfermedad si escapa al control de una autoridad central y, sobre todo, unificada, cuya representación geográfica es la ciudad de Buenos Aires. (Vezzetti, 1986, p. 104)

Nuestra lectura busca comprender las características locales de la recepción del psicoanálisis en Córdoba, introduciendo la dicotomía entre el interior y el puerto, que se suscitó en el proceso de centralización que caracterizó el nacimiento del Estado Nacional a partir de la década de 1880. En un proceso que se extendió, en medio del proceso inmigratorio, hasta entrado el siglo 
XX. A su vez, esta dicotomía tuvo una expresión en el plano cultural, asociando al progreso y a la ciudad de Buenos Aires a la cultura francesa, mientras que Córdoba y el resto del interior del país se expresaron en esa tensión apelando a las raíces hispánicas y criollas.

\section{España en la cultura de Córdoba y la recepción del psicoanálisis}

De particular implicancia en la caída del positivismo fue la aparición y difusión del humanismo vitalista que se instaló desde la presencia de una serie de intelectuales españoles. Ciertamente que las visitas de Eugenio D'Ors (1921) y de José Ortega y Gasset (1916) tuvieron un gran impacto en la intelectualidad cordobesa, siendo este último el principal personaje que conmovió la visión positivista en su visita a Argentina en 1916 (Plotkin, 2003, pp. 35-37). El español, en aquel encuentro, fue terminante en su crítica al positivismo. Hugo Klappenbach (1999) analiza el gran impacto que Ortega tuvo en su visita a la Argentina, al generar una apertura a una psicología filosófica, crítica del positivismo. Alejandro Korn y Coriolano Alberini afirmaban que Ortega fue la influencia definitiva al giro que se propició hacia 1918. Por otra parte, la Reforma Universitaria gestó un espacio democratizador, con la consiguiente proliferación de perspectivas diversas al positivismo ${ }^{4}$.

Es de importancia delimitar la presencia que Ortega y Gasset tuvo en Córdoba, no sólo porque implicó una apertura a líneas de pensamiento divergentes al positivismo, sino porque fue un difusor de las obras de Freud. Además, el pensamiento del español impactó directamente en gran parte de la joven intelectualidad cordobesa que fue partícipe de la Reforma del '18 y que posteriormente realizase las primeras lecturas de Freud en Córdoba. Hugo Vezzetti (1996) entendió la difusión que realizaron los españoles de la obra de Freud, haciendo hincapié en la figura del psiquiatra español Gonzalo Láfora y su influencia en la persona de Juan Beltrán. Ortega y Gasset fue un promotor importante de las teorías del vienés al prologar y promocionar la traducción de las obras de Freud (Plotkin, 2003, p. 68), aunque sostenía estas iniciativas no tanto por adherir al psicoanálisis, sino más bien para generar una atmósfera crítica y estimulante, que bien jugó su papel para socavar las durezas del positivismo imperante. Muchos

\footnotetext{
"Tales críticas aparecían contextualizadas en el marco de las nuevas reorientaciones filosóficas, que encontraron en la Reforma Universitaria en espacio académico adecuado para su desenvolvimiento..." (Klappenbach, 1999).
}

intelectuales cercanos a la figura de Ortega y Gasset, fueron también promotores de la primera lectura de Freud en España, no sólo Láfora y Sacristán, sino también Pi Suñer, Gregorio Marañón, César Juarros, José Sanchís Banús y luego Emilio Mira y López, entre otros (Plotkin, 2003, p. 69) .

\section{La influencia española en los primeros lectores de Freud en Córdoba}

En la visita de 1916 a la Argentina, Ortega y Gasset viajó a Córdoba y entró en contacto con Deodoro Roca ${ }^{6}$, quedando sorprendido por la figura intelectual del cordobés, de quien afirmó: "el argentino más eminente que conoc $\hat{\imath}$ ' (Sanguinetti, 2003, p. 10). El 14 de diciembre de 1916, Deodoro escribió a Ortega:

Esta mañana la universidad aprovechando la postergación de su viaje resolvió invitarlo a dar un curso en ésta. Hay gran entusiasmo. Nos preparamos renovar emociones inolvidables. Recuerdoló con cariño. Deodoro Roca. (Asenjo \& Gabardáin, 2002, p. 62)

Años después, el español retornó a la Argentina sin perder ocasión para visitar la provincia mediterránea; de allí en más, los jóvenes intelectuales de Córdoba y de España mantuvieron un permanente contacto. En la Revista de la Universidad Nacional de Córdoba (RUNC), órgano de difusión inaugurado por Martínez Paz, se publicaban textos de Ortega y Gasset, como Pedagogía de secreciones internas (Ortega \& Gasset, 1920). En el escrito, se sostenía una dura crítica al positivismo, la especialización, la tecnificación y

\footnotetext{
5 En España ya se había abierto la lectura de los textos de Freud a partir de un trabajo de Fernández Paz, en 1914, al final de la década ese espacio de discusión se acentuó en la medida en que algunos discípulos de Ramón y Cajal promovieron la idea de que en materia psicológica se estaban desarrollando grandes cambios. Dos discípulos de Cajal, según Thomas Glick, jugaron roles importantes en la recepción de las ideas de Freud: Gonzalo Láfora y José Sacristán, quienes ya desde 1918, escribían sobre temas freudianos en $\mathrm{El} \mathrm{Sol}$, el periódico español dirigido por Ortega \& Gasset (Glick, 1982).

6 Hasta hace unos años, la figura de Deodoro Roca no era muy conocida pero, tras una serie de investigaciones y publicaciones, sus efectos en la intelectualidad cordobesa y latinoamericana han sido reconocidos con amplitud (Argañaraz, 2007; Kohan, 1999; Sanguinetti, 2003). En torno a su seductora personalidad, se concentraron intelectuales de gran talla, el Conde Keyserling, Halla de la Torre, los hermanos Tuñón, Stefan Sweig, Manuel Gálvez, Martínez Estrada, Rafael Alberti, Pablo Neruda y, de particular injerencia, Eugenio D’Ors y Ortega \& Gasset.
} 
biologización de la vida humana, todos temas que se desplegaron en las obras de los jóvenes intelectuales cordobeses, Raúl, Jorge y Arturo Orgaz, Deodoro Roca, Juan Filloy, Arturo Capdevilla. Este grupo ya en 1916 había instalado la Asociación Córdoba Libre, antecedente de los movimientos que gestaron la Reforma Universitaria.

El pensamiento de Eugenio D'Ors fue de particular injerencia en la obra de Deodoro Roca. De hecho, Roca es quien promovió personalmente la presencia de Eugenio D'Ors, pues presentó el 10 de junio de 1920 un proyecto al Consejo Directivo de la Facultad de Derecho para que el español dictase sus seminarios ${ }^{7}$. Pero no sólo esto, sino que Deodoro proponía este viaje de Eugenio en la línea de influencia que tuvo la presencia de Rafael Altamira en Córdoba en 1909. Dicho viaje fue parte de un proyecto de difusión de la cultura española en América, tal como lo expresa Gustavo Prado:

...es imprescindible, por lo tanto, entender el Viaje y su repercusión en el marco de las relaciones intelectuales y culturales entre España y cada uno de los países visitados. (Prado, 2008, p. 195)

Es evidente que Deodoro promocionaba a la cultura y la intelectualidad españolas que tanto habían afectado a su formación. Tanto D'Ors, como Ortega y Gasset y Pí Suñer habían sostenido contacto con él. Deodoro llegó a indicar en De la fabla caballeresca, publicado en 1916, esa inmanencia de la cultura española:

Para sentirnos inundados de gloria preciso es tender muy lejos la mirada, evocar las grandes sombras lejanas, los varones enérgicos de otra edad: el Cid, Pizarro, Loyola, Don Quijote... Símbolos todos, de virtudes desaparecidas... (Adviértase que somos españoles por el corazón y por la raza). (Roca, 1916, p. 6)

Arturo Capdevilla, quien en cierto sentido desarrolló la misma estrategia de vulgarización que Antonio

\footnotetext{
Deodoro explica que quiere continuar con la benéfica influencia cultural que importó la presencia en Córdoba, de Rafael Altamira, José Ortega y Gasset y Augusto Pi Suñer. Para calcular los costos, ha escrito "al presidente de Asociación Española de Buenos Aires, que es quien trajo al profesor Pí Suñer". Votada su propuesta, se aprobará por unanimidad, en la sesión del 24 de junio. Al final, se pagarán a D’Ors, $\$ 4000$, por ordenanza $\mathrm{N}^{\circ} 41$, en la sesión de 16 de agosto de 1920 (Sanguinetti, 2003, p. 37).
}

Machado y Sanchez Mejía, ${ }^{8}$ al escribir una obra de teatro sobre Freud: Consumación de Sigmund Freud (1946), fue quien escribió los versos necrológicos en honor de Deodoro:

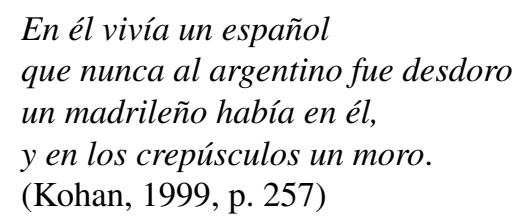

Ya avanzados los primeros pasos de la Reforma, D'Ors aceptó la invitación realizada para dar un curso de filosofía sistemática, respondiendo fundamentalmente por su interés de ser parte del pensamiento y accionar reformista 9 .

Klappenbach (2006, p. 4) cita la ponencia "La psychologie expérimentale dans la République Argentine", de Horacio Piñero, Profesor Titular de Fisiología en la Facultad de Medicina y Profesor Titular de Psicología en la Facultad de Filosofía y Letras, ambas en de la Universidad de Buenos Aires, quien afirmaba que: "Intelectualmente, somos en realidad franceses". Esta cita ha atravesado todos los estudios de historia de la psicología, la psiquiatría y el psicoanálisis en Argentina (Dagfal, 2009; Plotkin, 2003; Talak, 2000; Vezzetti, 1996). Todos ellos dejan en claro que es la cultura francesa la que ha impactado en Buenos Aires. Gregorio Bermann se formó en Buenos Aires y no en Córdoba, como lo hicieron Deodoro Roca, Jorge Orgaz, Juan Filloy y Arturo Capdevilla. De esta forma, en Bermann podemos encontrar un referente de lo que fue la recepción del psicoanálisis en Buenos Aires. Todas las historias del psicoanálisis en Buenos Aires, toman a este autor como un referente de la psiquiatría progresista cordobesa. No obstante, aunque desarrolló sus actividades en Córdoba, recibió el impacto de haberse formado en la capital. En este sentido, Bermann encarnó el esfuerzo civilizador que se extendió de

\footnotetext{
8 Mejía tenía contacto con Gonzalo Lafora, con quien se asesoraba para construir los personajes de su obra de teatro Sinrazón (1928) (Glick, 1982, p. 562).

9 Acepto, nos dijo, con placer la invitación de la Universidad argentina de Córdoba. Hace mucho tiempo que el Colegio Novecentista de Buenos Aires se comunica conmigo; Benjamín Taborga y sus amigos emprendieron los mismos caminos que nosotros los españoles novecentistas. Las Universidades argentinas están abiertas a las palpitaciones de la existencia pública, y en Córdoba secularizaremos la enseñanza en sí misma, llevando a ella, de una manera triunfal, un ímpetu de vida nueva.

Nuestra universidad española debería recoger de aquella otra Universidad su espíritu rebelde, ante la caducidad de que está rodeada (Palabras de Eugenio D’Ors, en La Nación, 23-3-1921)
} 
Sarmiento a Ingenieros, siendo la semilla que germinó en él de un origen francés y con sede en las propuestas de la sociedad médico-psicológica de París, de la cual era socio. Bermann formaba parte de ese grupo de jóvenes intelectuales socialistas que habían sido estimulados por las ideas de Ingenieros, quien a su vez sostenía una fuerte admiración por el continente europeo, particularmente por Francia y las ideas janetianas. Ingenieros respondía al europeizante proyecto de Sarmiento y algo de esa savia afectaba a Bermann, quien invocaba la figura de Sarmiento; además, sostenía una visión del criollo muy desvalorizada:

...ya insistió Carlos Octavio Bunge sobre esta pereza criolla que atribuye a una falta innata de actividad, tan diferente a la pereza europea que es un derroche de energía en cosas inútiles. Cuando Darwin indujo a un gaucho que pasaba sesteando los días y jugando las noches a que empleara mejor su tiempo, a que trabajase, éste le contestó: "jes tan largo el día!" [...] el ocio criollo puede manifestarse bajo la forma de la más completa inacción, o de la falta de disciplina y de higiene mental en el trabajo. (Bermann, 1934, pp. 82-83)

Era una visión ligada directamente a la interpretación sarmientina del interior. En definitiva, Bermann fue un exponente claro de un modo de adopción del psicoanálisis que Vezzetti y Plotkin bien han descrito para lo sucedido en Buenos Aires, receptado por una corriente progresista, a veces positivo naturalista, particularmente influenciado por la cultura europea, específicamente francesa.

Por ello es que D'Ors encontró en Gregorio Bermann un opositor intelectual. Inicialmente, consideró que su filosofía era un género literario que se amparaba en un "dualismo rústico" que no contemplaba a los evidentes resultados arrojados por Darwin y el problema del origen de las especies. Bermann atacó también a Ortega y Gasset:

Lo dificultoso es que una personalidad de esta orientación haga su filosofía más o menos propia y original, y en esto el Sr. D'Ors, siguiendo las huellas brillantes de Ortega y Gasset, va triunfando, porque hay robusta coherencia entre las partes de su sistema, pero se olvida en él de la verdad léanse en cambio algunos de los filósofos contemporáneos y hombres de ciencia de criterio filosófico, no digo los de primera magnitud, hablo de Guyau, Bain, Ribot, Durkheim, Jakob, Höffding, Baldwin, Duhem. ¡Qué riqueza intelectual, cómo ahondan realmente los problemas, qué majestuoso el cauce de su pensamiento! Entonces se ve bien que el señor D’Ors es sólo un original periodista de la Filosofía. (Bermann, 1921, pp. 494-495)

En definitiva, Bermann identificó a Eugenio D’Ors en la línea de Ortega y Gasset, de quien, a pesar de su admiración por el intelectual, afirmaba es un "degenerado erótico" (Campomar, 2003, p. 232). Dejaba en claro una posición que, si bien criticaba al positivismo del siglo XIX, defendía los postulados de una renovación materialista, en particular en su tesis de doctorado de 1920, El determinismo en la ciencia y en la vida. Tal es así, que los desacuerdos que esgrimía en contra de los pensadores españoles, le llevaron a tener una fuerte disputa con Deodoro Roca, a tal punto que se separaron por casi una década. Luego, tras el desafortunado suceso de la muerte del hijo recién nacido de Bermann, Deodoro le mandaría unas líneas afectuosas y volverían a entablar amistad.

Así como Deodoro Roca había sido un intelectual de la primera hora de la Reforma Universitaria, el hoy olvidado Saúl Taborda fue parte fundamental de aquella revuelta política. Fue en 1935 que sus Ideas Pedagógicas y su concepción filosófica históricapolítica cobraron consistencia. Fue el año en que comenzó a publicar la revista Facundo; con su apertura: "Meditación de Barranca Yaco", inició su doctrina del "facundismo" o "comunalismo federalista". Allí lanzó una reivindicación de los caudillos y destacó las figuras del Bustos y Urquiza, entablando una discusión con la pedagogía positivista y de exportación cultural, francesa por antonomasia, que era postulado por Buenos Aires y Sarmiento;

Taborda [...] reivindicaba lo mejor del legado castellano: la democracia medieval de Castilla de la Reconquista, basada en la colonización de la meseta castellanoleonesa- la "presura"- hecha por los liberales campesinos que sólo se asentaron en ella para afrontar el Islam cuando las cartas Pueblas y los Fueros le aseguraron su independencia. Como productor y como ciudadano [...] serían estas libres comunidades hispánicas, reproducidas en América por la colonización española, las que tendrían presente Taborda al elaborar años después su teoría del "comunalismo federalista y el "facundismo". (Ferrero, 1988, p. 122) 
Esta forma de nacionalismo en ningún modo estuvo alineada con el nacionalismo ultracatólico en el que se había enrolado Lugones.

Si Bermann criticaba a la cultura gaucha en virtud de la cultura francesa, Filloy exaltaba al Martín Fierro en contra de las interpretaciones de Borges ${ }^{10} \mathrm{y}$ se comprometió por sobre todas las cosas con la experiencia autóctona, ligada a las raíces criollas:

... se reunió en Córdoba el Segundo Congreso de la Saciedad Argentina de Escritores (12-14 de octubre, 1939), presidido por el doctor Juan Filloy, que desde su Río Cuarto realizaba una obra literaria de trascendencia y daba a las prensas originales volúmenes: "Balumba", "Periplo", "Estafen", etcétera. En aquella reunión de escritores, Filloy hizo afirmaciones que tuvieron amplitud de futuro, al decir que era "necesario provincializar la literatura nacional. Porque quien diga que tenemos un arte propio, miente. Arte mestizo, sî́". Y argumentó: "Para nacionalizar nuestras letras es menester provincializarlas; insurgir en montonera contra-la absorción metropolitana", cerrando su pensamiento con estos

10 “- ¿Usted dijo alguna vez que Borges era un escritor de laboratorio, al que le había faltado vida?

- Claro, ésa es su falla básica porque tuvo una educación muy limitada, a cargo de gobernantas inglesas y francesas. Su visión sobre la vida nacional fue muy rudimentaria; le faltó contaminación con la realidad y el paisaje, con la tradición popular argentina. Así como escribió con tenacidad literatura inglesa, tuvo un criterio despectivo sobre el Martín Fierro.

-Ya que estamos, ¿cuál es su opinión acerca del Martín Fierro?

- Creo que es una obra fundamental que nos representa y que permanecerá firme. Para toda la muchachada que lo leímos, Martín Fierro fue una figura rebelde que coincidió plenamente con nuestras vehemencias juveniles; que participó en la gestación del espíritu nacional porque iluminó una época en la que la nación no estaba aún consolidada. Es un poema épico, realizado con una gran habilidad, con versos netamente argentinos, sin alusión ni semejanza con el romancero español. Está escrito en quintillas o sextinas típicamente suyas, con una combinación métrica perfecta. Tiene sus incorrecciones y licencias, por cierto, pero en general son versos muy correctos. Todo esto con una magnífica inspiración y acopio de experiencias para describir los caracteres humanos... Borges equiparaba a Fierro con Juan Moreira. Error flagrante. Son arquetipos distintos. Martín Fierro es un personaje discutible pero simbólico. Moreira, un matón de comité. Aquél prevalecerá porque tuvo rebeldías valiosas y ciertos impulsos cuestionadores. Por lo demás, amén de la genialidad condensada en su Martín Fierro, José Hernández fue un escritor que hizo todo lo posible por exaltar las industrias agrarias del país. Ambos afanes son deudas que no caducan" (Ambort, 1992). conceptos: "Los escritores, en su afán de atalayar rutas ancestrales, viven asomados hacia Europa, desde el balcón atlántico de Buenos Aires". (Bischoff, 1977, p. 471)

En este sentido, la cultura francesa proliferó con tenacidad en Buenos Aires:

Victoria Ocampo confesaba en el $\mathrm{N}^{\circ} 1$ de Sur que el español de Rubén Darío -uno de los grandes poetas de la lengua- le parecía "de un mal gusto intolerable, una parodia de Verlaine".

Ella prefería el francés, porque "en mi medio y en mi generación las mujeres leían casi exclusivamente en francés... y mi habla, mi español, era primitivo, salvaje". Jorge Luis Borges, por su parte, se educaba bajo la influencia del inglés. Eran los resultados de la educación extranjerizante que se daba a sí misma una oligarquía que había vuelto sus espaldas al país. Esta clase, bárbara en realidad aunque se creyera el paradigma de la civilización de la Plata, pensaba que el castellano "era un idioma impropio para expresar lo que no constituía el lado puramente material, práctico de la vida". (Ferrero, 1998, p. 143)

Borges fue quien entabló una querella literaria con Arturo Capdevilla, el autor de Consumación de Sigmund Freud (1946), justamente poniendo en cuestión las raíces culturales de la Argentina:

Lo que hace Capdevila -en Babel y el castellano (1929)- es establecer la filiación materna con España y definir la nacionalidad a partir de dicho vínculo. El idioma castellano es esa matriz. Pero maternidad española no quiere decir minoridad argentina [...] por cierto que es la elíptica acusación lanzada por Borges. [...] todavía más, de ningún modo es renuente a manifestar su íntima convicción de que el auténtico patriotismo debe ser español, incluso en escala política. (Oviedo, 2008, pp. 129-130)

Para Jorge Orgaz, España era un punto de incisiva influencia; sus textos dejan ver constantes alusiones a Ortega y Gasset y, en particular, una fascinación por Unamuno, sobre el cual escribió un análisis psicológico 
que demandó un estudio exhaustivo y meticuloso de la obra y la vida del español, titulado Unamuno y sus espejos (1970). Es sabido también que la figura de Unamuno era un común denominador en los encuentros del sótano de Deodoro (Argañaraz, 2007, p. 155). Marañón sostenía en España el movimiento de reforma sexual en el que Jiménez de Asúa participaba, y la existencia de varios libros de Marañón en la biblioteca de Orgaz indica su gran interés. Encontramos el temprano libro de Marañón, llamado La edad crítica (1919), en el que consta de puño y letra de Jorge Orgaz haber sido leído en 1921. Ya en ese trabajo se mencionaba a Freud. De especial gravitación, encontramos en su biblioteca personal el volumen arduamente trabajado por Orgaz, de Amiel. Un estudio sobre la Timidez, de Gregorio Marañón (1932). Este texto fue leído por Orgaz en 1932 y tuvo incidencia en La vida como enfermedad (Orgaz, 1934). Al parecer, Orgaz tomó el modo de escritura de Marañón: así como "Amiel" fue para Marañón tópico de análisis psicoanalítico, "Romagosa" lo fue en clave autobiográfica para Orgaz, en su Memoria de Ciudad Chica (1978). Laín Entralgo también fue una referencia importante en la obra de Orgaz, de quien extrajo las críticas a una medicina subsumida por la técnica. Del mismo modo en que Unamuno dudaba de la existencia de Dios, Orgaz se debatió algunas veces con la fe, aunque el ateísmo se hizo presente con mayor insistencia. En su archivo personal, encontramos varias cartas que lo hicieron partícipe de algunos diálogos con personajes ligados a la religión y al anti-reformismo. Incluso libros enviados por entidades religiosas que proponían una charla sobre la Biblia y la Medicina, en donde se trataba el tema del psicoanálisis. Aunque sus diferencias políticas lo hayan distanciado de tales relaciones, en el fuero íntimo, la caridad fue punto recurrente en su obra como médico.

Vale decir, si la cultura francesa había tenido un fuerte impacto en Argentina, en Buenos Aires se hizo ineludible, mientras que en Córdoba la cultura española se erigió con mayor regularidad. En este sentido, como se habrá notado, estas diferencias no carecen de tensiones y plantean, nuevamente, una distancia entre el espacio mediterráneo y el puerto. Estas líneas sobre la presencia de la cultura y la intelectualidad española en los primeros lectores de Freud en Córdoba debieran profundizarse con un estudio más completo. Sin embargo, nos permite fundamentar algunos puntos respecto de las peculiaridades de la recepción de Freud.

Entonces, nos encontramos con tres ejes para comprender las relaciones y tensiones en las que se sumergieron las letras de Freud en Córdoba: 1) El positivismo y su recepción; 2) La cultura hispánica, y 3) la impronta del nacionalismo ultracatólico.

Hasta aquí vimos cómo la presencia de Ortega y Gasset impacta en la intelectualidad argentina y, en particular, la cordobesa. Pero no fue sólo Ortega, sino toda una línea de intelectuales españoles, con quienes se gestó una vinculación intelectual y política particular. A su vez, pudimos ver cómo el discurso humanista español impactó también en la intelectualidad neotomista y cómo se dio una reacción materialista por parte de Bermann.

\section{Lecturas de Freud en Córdoba}

La lectura de la recepción del psicoanálisis en Córdoba que aquí mostramos, presenta una triple división. Por un lado tendremos una recepción propiamente médica, afectada por lecturas francesas y orientadas por un positivismo de corte social. Tal como sucedió en Buenos Aires, varios médicos mostrarán la asimilación de Freud al arsenal terapéutico de una de las ramas menos favorecidas de la medicina: la psiquiatría. En esta línea tanto Gregorio Bermann como Conrado Ferrer buscaron una articulación entre la educación y la medicina. Desde el extremo de los problemas pedagógicos, Leonilda Barrancos de Bermann también bogaría por una renovación de la educación instrumentada por la psicoterapia y el psicoanálisis. Esta vía es la más conocida, sin embargo, una segunda línea de interpretación de la obra de Freud se abrió en Córdoba. Ligada a una profunda influencia de las filosofías vitalistas de Ortega y Gasset y Eugenio D'Ors, encontraría inspiración en líneas interpretativas como las de Stefan Sweig, el Conde Keyserling y Unamuno. Allí se exalta la cultura española como referencia cultural preferible a la influencia francesa. Representantes de esta línea de interpretación son Deodoro Roca, Juan Filloy, Jorge Orgaz, Saúl Taborda, Arturo Capdevilla. Ambas líneas estaban ligadas al fenómeno cultural de la Reforma Universitaria que se suscitó en 1918, como parte de un proceso de democratización de los espacios institucionales en Argentina.

Una tercera lectura de la obra del vienés, la produjo la corriente contra-revolucionaria, que, al contrario a lo sucedido en Buenos Aires, ofreció un rechazo contundente a las ideas de Freud. A su vez tuvo gran influencia y efectividad, por tener gran injerencia en todas las facetas institucionales y culturales de 
Córdoba. Esta línea estuvo representada por Filemón Castellano, Héctor Luís Torti, Nímio de Anquín y Francisco Tórres.

\section{Del primer freudismo y la medicina en Córdoba}

Los trabajos de Plotkin (2003) brindan una periodización en tres etapas de la introducción del psicoanálisis en Buenos Aires. En lo que Plotkin ha delimitado como la primera etapa en la introducción del psicoanálisis en Argentina, esto es, desde la década del diez a mediados de la década del veinte, en Córdoba vemos las primeras lecturas lacónicas de la obra de Freud. Benito Soria, profesor de pediatría y clínica infantil, que realiza un viaje a Francia en 1910, muestra en "Sueño y ensueño en la segunda infancia", un capítulo de "Psicopatología infantil" (1915), en referencia a los estudios sobre la histeria de Freud y Breuer, citándolo en alemán. Un año después, Alberto Stucchi mencionará a Freud en "Manual de medicina legal" (1916), en un párrafo dedicado a las perversiones, sin citar referencias bibliográficas específicas. A fines de la década del veinte, el padre José María Liqueno, escribe su "Compendio de Psicología Contemporánea" (1919), en el que, a colación del problema de los sueños en tanto formaciones de deseo, menciona las doctrinas de Freud. Ninguna de estas referencias implicó una lectura sistemática de la obra de Freud.

Dentro de esta primera etapa, encontramos a Gregorio Bermann, quien accedió a la cátedra de Toxicomanía y Medicina Legal poco tiempo después de instalarse en la ciudad de Córdoba, en 1922. Sin dudas fue quién realizó lecturas más profundas y sistemáticas, incluyendo al psicoanálisis como una herramienta de una psiquiatría organicista de corte social (Ferrari, 2012). Desde inicios de la década del 20 se podrán ver algunas referencias sobre el psicoanálisis en su tesis de medicina "El determinismo en la ciencia y en la vida" (1920). En esta primera etapa, el psicoanálisis no tiene un gran impacto en la medicina de Córdoba, y no es sino hasta el final de la década del 30 que comienza a manifestarse con mayor incidencia. Luego, escribiría "Toxicomanías" (1926), texto que descansa en la biblioteca de Freud, en donde desarrolla algunos aspectos psicológicos del consumo de sustancias a partir de la obra del vienés. El mismo año que publica Toxicomanías, brinda una conferencia que tuvo un gran alcance, pues fue editada en dos ocasiones: "Psicogénesis de la locura moral. Disertación en el Instituto popular de Conferencias" (Bermann, 1934b). En ese texto, expuesto en 1928, marcaba el inicio de las críticas a las tesis degeneracionistas y se implicaban con una etiología social de la locura. Esta línea fue desarrollada por el último José Ingenieros en Buenos Aires y adoptada críticamente por Bermann.

Conrado Ferrer, médico del Hospital Colonia de Oliva, publica en la Revista de la Universidad Nacional de Córdoba (RUNC) "El temperamento autista en algunos adolescentes" (1931). En ese texto muestra las implicancias de la higiene mental en la conformación del adolescente, y la importancia de la utilización de criterios médicos al momento de formar a los docentes. Allí aparece la figura de Freud, pero sobre todo la del disidente Alfred Adler y Jung. En esa misma línea, Leonilda Barrancos de Bermann, quien había viajado con su esposo Gregorio Bermann a Alemania en 1930, publica en la RUNC “La reforma educacional en Austria" (1931). También proponiendo la reforma educativa a partir de la Escuela Nueva y promoviendo las ideas de Freud para comprender la familia y la educación infantil. A fines de la década del 30, Bermann publicaría su ya mítica revista Psicoterapia en la que escribe dos artículos que muestran al psicoanálisis, como una herramienta más del instrumental psiquiátrico. Los dos textos son: "Patogenia de la neurosis obsesiva" (1936a) y "Sobre la resistencia en psiconeurosis. Los neurópatas que 'no quieren' curar" (1936b). Estos textos muestran las características de la recepción del psicoanálisis que tanto Plotkin (2003), Vezzetti (1996), García (1978), Gentile (2000), han propuesto para lo ocurrido en Buenos Aires en los ámbitos médicos y del pensamiento de izquierda. Como hemos dicho, Bermann se había formado en la capital, y tenía especial atracción por la cultura francesa. En otra vía de recepción, un grupo de médicos, juristas, abogados, intelectuales y literatos, que como ya hemos mostrado habían sido influenciados por la cultura española, brindarían una recepción de las ideas de Freud un tanto diferentes.

\section{Freud en clave vitalista española: de la literatura a la clínica médica}

Deodoro Roca, abogado e intelectual mentor de la Reforma Universitaria de 1918, nunca escribió un libro, se dedicó a la crítica literaria, política y filosófica desde su revista Flecha y ofreció una serie de escritos en donde la filosofía española y Freud 
tuvieron su confluencia. Fueron escritos cortos y punzantes dedicados al análisis de la cotidianeidad. En sus épocas de docente universitario dictó la materia Filosofía general, en la Facultad de Derecho. Su programa de 1920 no integra a la figura de Freud, incluso en el apartado "Nuevas orientaciones" se dedicaba a discutir en su bolilla XII "El predominio de la psicología - Wundt", "XIII Nietzsche", "El pragmatismo. James" (Kohan, 1999, pp. 131-132). No obstante, a partir de fines de la década del 20, Freud comienza a formar parte de su lectura vitalista. Dentro de su prolífica producción escrita dedicó tan sólo cuatro notas a la figura de Freud: "El psicólogo de las neurosis" (1929), "Impulso y contención" (1930), De Goethe a Freud (1931) y "Docotomía y sacerdocio" (1930). Tales textos han sido enmarcados por el vitalismo D'Orsiano y las doctrinas de Ortega y Gasset. Varios estudios han delimitado la importancia y originalidad de los textos de Deodoro, sus tempranas lecturas de Nietszche, Marx y Freud (Argañaraz, 2007; Ferrari, 2012; Kohan, 1999; Sanguinetti, 2003). En estos escritos resalta el uso vitalista de la teoría de la sexualidad de Freud. A su vez la obra del vienés no ha sido integrada sistemáticamente, sino que aparece esporádicamente sin preocuparse de articulaciones teóricas coherentes.

Juan Filloy, abogado y Juez radicado en la ciudad de Río Cuarto, provincia de Córdoba, introduce a Freud en su prolífica obra literaria, en especial en "¿Estafen!" (1931), “Op Oloop" (1934) y “Caterva” (1938). Casi al mismo tiempo en que Roberto Arlt, expondría personajes del bajo fondo citadino haciendo un doble uso de las ideas de Freud. Por un lado criticaría al psicoanálisis como parte de la maquinaria psiquiátrica, y en este punto podría ser un claro opositor a las propuestas de Gregorio Bermann, así como también para comprender aspectos de la psiquis normal a partir de personajes de baja estofa.

Fue justamente a esta configuración de saberes a las que Filloy criticó desde la literatura:

Cuando en las horas de obligado descanso me compenetro de los progresos técnicos de las policías de Europa y Estados Unidos, verdaderamente me crispa el destino de mis colegas. Son las peores víctimas de la observación y la estadística. La antropometría, el behaviorismo, el psicoanálisis, la eugenesia, etc., los aprehenden y someten a experimentaciones ominosas. ¡No hay respeto por la individualidad! ¡Es intolerable! Aquello es el fichaje más infame del cuerpo y del espíritu... (Filloy, 1932, p. 14)

Havelock Ellis, Kraff Ebbing, Kretschmer, fueron las referencias en las que se enmarcó un psicoanálisis que instrumentó la civilización del crimen y la locura. Pero, en la obra literaria de Filloy prevalecía una crítica al dispositivo jurídico y al nexo íntimo que lo ligaba al saber psiquiátrico.

Dentro de la literatura y la crítica literaria argentinas de los años '30, Freud fue un referente escaso. Plotkin da cuenta de esta realidad al referenciar la obra de Roberto Arlt como uno de los únicos literatos que incluyeron visiones populares de la figura y la obra de Freud. Efectivamente, Erdosain el personaje nuclear de "Los siete locos", de 1929, y de su secuela "Los Lanzallamas", de 1931, es objeto de la elucidación de sus deseos inconscientes. Plotkin menciona que en la ensayística de la década del '30 tuvo una recepción más profusa del psicoanálisis. En particular, con la obra de Ezequiel Martínez Estrada "Radiografía de la Pampa" (1933) (Plotkin, 2003, p. 59).

Dentro de los órganos de difusión, Sur, la reconocida revista editada por Victoria Ocampo, publicó algunos artículos en honor a Freud, en 1936, junto a la reconocida revista Psicoterapia, editada en Córdoba, quienes conmemoran los 80 años de vida del creador del psicoanálisis. Elías Castelnuovo, uno de los intelectuales de izquierda referente de la recepción negativa de Freud en Buenos Aires, criticó a Freud en la revista Claridad. Raúl Gonzales Tuñón, quien estaba en contacto con Deodoro Roca y el grupo reformista, fundó en 1933 la revista Contra, que promovía una lectura de Freud como teoría liberadora. La revista Nosotros receptó a la figura de Freud de un modo positivo, al contrario que el proyecto Martín Fierro, en donde el vienés no tuvo cabida. El artículo de José Mariátegui "El freudismo en la literatura contemporánea", en la revista de La Plata, Sagitario, en 1927, fue una de las pocas articulaciones entre literatura y freudismo. En este marco, tal como hemos planteado (Guerrero \& Ferrari, 2006), Filloy se constituye en una de las articulaciones entre freudismo y literatura de mayor implicancia en el campo literario argentino de los tempranos ' 30 .

La obra literaria de Filloy, como veremos, es una crítica a una forma de adopción del psicoanálisis, ligado a la medicina y a la criminología, que fue característico en Buenos Aires. Esta forma de asimilación fue criticada desde una línea filosófica animada por el vitalismo. 
El campo de la filosofía también alimenta a la narrativa. En ese plano el "élan sexual freudiano" es convocado junto a la metafísica de Hegel y al vitalismo de Bergson. En esa pluralidad de saberes donde conviven filosofía, literatura, psiquiatría, derecho, y política asoma el psicoanálisis, para insertarse como teoría que permitiría el análisis de temas que desde Ingenieros se venían imponiendo en el mundo cultural y académico, tales como los sueños y la psicopatología sexual. (Argañaraz, 2007, p. 59)

La presencia de la obra del vienés en la narrativa de Filloy tuvo dos registros bien claros. En una instancia se puede ver al psicoanálisis como parte del instrumental psiquiátrico en la maquinaria judicial. En este sentido, los personajes de sus obras son emisarios de una crítica a la obscenidad de la justicia. Es una crítica dirigida, justamente, al tipo de uso que Bermann había hecho de la obra de Freud. En un segundo registro, la obra del vienés aparece para interpretar al submundo del crimen, de los instintos, la sexualidad y los deseos. Pero no como parte del dispositivo psiquiátrico, sino como una interpretación de esa realidad, cuyos personajes emergen del cieno de la sexualidad para protagonizar una subversión en contra el orden burgués. En algún sentido, encuentra esta vía una identificación con las producciones de Arlt, ya analizadas por Plotkin (2003), Vezzetti (1996), Guerrero y Ferrari (2006) y Argañaraz (2007). Finalmente, es esa revuelta de los bajos instintos, esa crítica a los grandes ideales y al progreso que anima al status quo burgués y a la lógica positivista, la que puede detectarse como denominador común a todas sus obras. La locura y la enfermedad tienen un lugar valorado dentro de esta lógica:

—Sí. Claro que sí. La enfermedad se sobrelleva mejor.

[...]

-Oh, me enervas ya! Honras al vicio como un perdulario cualquiera. ¿Dónde está tu honor?

-Yo tenía un perrito que se llamaba Honor. La interrupción del Estudiante, emitida simplemente, por decir algo, resultó más graciosa por lo inopinada. (Filloy, 1943, p. 168)

Es entonces allí adonde apunta el anarquismo filloyano, muy cercano a las revoluciones de la plebe porteña que reclamaba Roberto Arlt.
La psicopatología freudiana, en su cercanía con las psicopatías sexuales, encuentra manifestación en "Caterva" (Guerrero, 2008), en donde el submundo urbano filosofa y se expresa como la consistencia en la que se asientan las opulencias de la burguesía. Son parte de una banda de Moebius en las que el capitalismo, el cientificismo y el moralismo se expresan en la misma cara de la perversión y la locura que ellos fabrican y ocultan. En esa denuncia, que la obra de Filloy hace explicita, la locura se sustrae a todo sistema de clasificación: "Si al menos supieran que tengo una locura para mi uso personal, tan singular en todo que aún no ha sido catalogada... Si al menos..." (Filloy, 1930, p. 104).

Esto indica el lugar revolucionario que la experiencia de la literatura induce: Freud es parte de una aprehensión filosófico-literaria de la realidad. Entonces, si el psicoanálisis encontró dos planos de expresión en la obra de Filloy, uno como parte del dispositivo psiquiátrico, en el cual es objeto de crítica; en el otro plano, Freud es ubicado en la experiencia literaria como crítica a esa forma de apropiación de la obra del vienés. En este sentido, es parte de una propuesta literaria que incluye a Constant, Goethe, Stendhal y Proust, en donde: "Freud se ha contraído a perforar la profundidad inédita de la subconsciencia..." (Filloy, 1934, p. 165).

También se suma a estas pocas obras literarias que incluyen a Freud en Argentina, el caso del poeta cordobés Arturo Capdevila, con su obra teatral "La consumación de Sigmund Freud" (1946), obra que llegó a hacerse oír en la APA (Asociación Psicoanalítica Argentina) (Plotkin, 2003). Como mencionamos, Capdevila también rechaza a la cultura francesa y promueve el lenguaje castellano y la vuelta a las raíces hispánicas. De hecho su obra teatral en cierto sentido desarrolló la misma estrategia de vulgarización que Antonio Machado y Sánchez Mejía en España ${ }^{11}$. Íntimamente ligado a la familia de Gregorio Bermann solía pasar temporadas en la casa de éste. Luego entablarán una discusión en ocasión del distanciamiento de Gregorio Bermann a fines de la década del cuarenta cuando, influenciado por la psiquiatría francesa de izquierda enraizada en la revista L'Évolution Psychiatrique, tildase de idealista y burgués al psicoanálisis.

Jorge Orgaz, reformista, profesor de Patología y Clínica Médica, que tras ser apartado de estos cargos por el gobierno de Perón, fue rector de la Universidad Nacional de Córdoba desde 1958 a 1964, introduce

\footnotetext{
11 Mejía tenía contacto con Gonzalo Lafora, con quien se asesoraba para construir los personajes de su obra de teatro Sinrazón (1928) (Glick, 1982, p. 562).
} 
a Freud en sus escritos médicos y autobiográficos. Orgaz aplicó el saber freudiano como una tecnología de análisis de las propias prácticas médicas. Como veremos, Orgaz, en clave autobiográfica, entendió al psicoanálisis como revelador de los procesos que subyacían al poder de la palabra en el acontecimiento de la enfermedad. De esta forma, entendió al médico como formando parte de ese acontecimiento y ese proceso de salud y enfermedad, en una visión del médico que era horizontal respecto de su paciente, lo cual tradujo inicialmente en "La vida como enfermedad" (1934) y luego en "Profesión y vida" (1942), "En torno al escritor" (1966) y "La clínica y el médico" (1966). Para Jorge Orgaz, España era un punto de incisiva influencia; sus textos dejan ver constantes alusiones a Ortega y Gasset y, en particular, una fascinación por Unamuno, sobre el cual escribió un análisis psicológico que demandó un estudio exhaustivo y meticuloso de la obra y la vida del español, titulado "Unamuno y sus espejos" (1970). Es sabido también que la figura de Unamuno era un común denominador en los encuentros del sótano de Deodoro (Argañaraz, 2007, p. 155). Como hemos mencionado, Marañón sostenía en España el movimiento de reforma sexual. La existencia de varios libros de Marañón en la biblioteca de Orgaz indica gran interés. Encontramos el temprano libro de Marañón, llamado La edad crítica (1919), en el que consta de puño y letra de Jorge Orgaz haber sido leído en 1921. Ya en ese trabajo se mencionaba a Freud. De especial gravitación, encontramos en su biblioteca personal el volumen arduamente trabajado por Orgaz, de "Amiel. Un estudio sobre la Timidez", de Gregorio Marañón (1932). Este texto fue leído por Orgaz en 1932 y tuvo incidencia en "La vida como enfermedad" (Orgaz, 1934).

Al parecer, Orgaz tomó el modo de escritura de Marañón: así como "Amiel" fue para Marañón tópico de análisis psicoanalítico, "Romagosa" lo fue en clave autobiográfica para Orgaz, en su "Memoria de Ciudad Chica" (1978). Laín Entralgo también fue una referencia importante en la obra de Orgaz, de quien extrajo las críticas a una medicina subsumida por la técnica. Del mismo modo en que Unamuno dudaba de la existencia de Dios, Orgaz se debatió algunas veces con la fe, aunque el ateísmo se hizo presente con mayor insistencia. En su archivo personal, encontramos varias cartas que lo hicieron partícipe de algunos diálogos con personajes ligados a la religión y al anti-reformismo, incluso, libros enviados por entidades religiosas que proponían una charla sobre la Biblia y la Medicina, en donde se trataba el tema del psicoanálisis. Aunque sus diferencias políticas lo hayan distanciado de tales relaciones, en el fuero íntimo, la caridad fue punto recurrente en su obra como médico.

Dentro de la apropiación médica del freudismo en Córdoba, encontramos a Gregorio Bermann, Conrado Ferrer y Jorge Orgaz. Los dos primeros estaban asociados a la psiquiatría y fue Bermann el gran referente que continuaba estando ligado a los modos de apropiación que se dieron en Buenos Aires, en donde se formó en filosofía y medicina. Jorge Orgaz fue el único que obtuvo su formación en Córdoba y había vivido toda su vida en la ciudad mediterránea, acompañado por Arturo Capdevilla, su entrañable amigo. Ya hemos mostrado la reticencia de Bermann al pensamiento vitalista español; en este sentido, se presentaba como una extensión de las vicisitudes del saber médico bonaerense, particularmente ligado a la tradición positivista de Ingenieros. La apropiación que Bermann realizó tiene un claro destino al discurso de Freud, al que incluye dentro del arsenal médico psiquiátrico. En Orgaz, la forma de apropiación fue diametralmente distinta pues se alejó del modelo psicosomático y de la sugestión para introducir la obra de Freud en una práctica médica que contemplaba más bien los alcances del uso de la transferencia en el proceso de salud-enfermedad y, lo que es más importante, reconoció los aspectos metapsicológicos de la teoría freudiana, al incorporarlos a un ejercicio del autoanálisis por la vía de la autobiografía y la literatura. Esto fue posibilitado por la gran influencia de la intelectualidad española, en especial la obra de Unamuno. Juan Argañaraz (2007) aclaró que Orgaz es inasimilable a lo que Gentile (2003) denomina freudismo médico. Emilio Pizarro Crespo y Lelio Zeno desarrollaron una aprehensión del psicoanálisis en la práctica médica en la que la psicosomática dominaba la escena. En clara oposición, Orgaz rechazó este concepto:

La clínica, que ha enseñado a la medicina y al a clínico a ver en el hombre una unidad psicosomática, enseña ahora que ese dualismo es falso, convencional, no sólo porque desvirtúa la idea de unidad que defiende sino, principalmente, porque el hombre es algo más que una unidad, cualquiera sea su estructura: es unidad en vital de pendencia social. No se concibe al hombre sano sin sociedad. A este respecto Werner Wolff sintetizó la trascendencia vital de tal hipótesis situacional: “...el hombre no vive en el vacío”. (Orgaz, 1966, p. 53) 
Finalmente, Saúl Taborda ${ }^{12}$, un intelectual olvidado, , aunque no tuvo mucho impacto en la política educativa argentina, es de relevancia para nuestro estudio en la medida en que incorporó el freudismo en sus producciones. Lo que es más importante, su filosofía localista denunció todas aquellas relaciones de poder que hemos descripto en los capítulos anteriores. Si en el punto anterior pudimos mostrar el modo en que se gestaron las tensiones entre un discurso médico positivista, la filosofía neotomista y el discurso religioso y, finalmente, un discurso minoritario ligado al vitalismo orteguiano que se oponía a ambos al tiempo en que adoptaba las ideas de Freud en el ámbito de la criminalidad, ahora encontramos esta misma estructura en el ámbito de la educación. Saúl Taborda fue quien, afectado por la cultura y la filosofía españolas, se opuso a las políticas sarmientinas de importación de la cultura francesa. De hecho, en el primer viaje de Ortega a Córdoba, éste le recomendó un itinerario de formación en Europa, que llevó a cabo entre 1923 y 1927. La obra de Eugenio D'Ors fue esencial también en su formación y en sus propuestas político-pedagógicas (Taborda, 1922). En esta vía, mantuvo intercambios con Alejandro Korn, quien como es conocido, lideraba, junto a Coriolano Alberini, la denominada reacción antipositivista. Luego de la Reforma Universitaria, en 1921, fue designado como Rector del Colegio Nacional de La Plata, allí se instaló junto al joven Carlos Astrada, que dictaba la materia Psicología. Taborda se introdujo en un medio cultural diverso a Córdoba:

En la capital bonaerense - a diferencia de lo ocurrido en Córdoba, donde debió enfrentar a la jerarquía eclesiástica y a la aristocracia católica-, "la juventud debió luchar a su turno contra la oligarquía liberal, positivista y cientificista", como indica Gabriel del Mazo, que contempló de cerca los hechos en su calidad de presidente de la FUA que era entonces. (Ferrero, 1988, p. 57)

\footnotetext{
12 Taborda (1885-1944), nacido en un Chañar Ladeado, provincia de Córdoba, comenzó sus estudios en la Escuela Normal de Córdoba y luego en el Colegio Nacional de Rosario. Continuó sus estudios de abogacía en La Plata, finalizándolos en 1908. En 1913 se doctoró en Derecho y Ciencias Sociales en la Universidad del Litoral y dictó clases como profesor de Sociología. En 1909, inauguró un período de producciones literarias que culminaron con la publicación de la novela Julián Vargas, en 1918. En ese mismo año, publicó "Reflexiones sobre el ideal político de América", y participó en la Reforma Universitaria, junto a Deodoro Roca, con quien mantenía una relación de cercanía.
}

Allí fue protagonista de un prolongado conflicto, pues promoviendo la organización estudiantil fue motejado de anarquista y se le solicitó apartarse de su cargo, cosa que rechazó, pero no pudo evitar ser expulsado. En aquel trance, Alejandro Korn apoyó al cordobés. Tras esta experiencia, realizó el viaje de formación a Europa y, a su regreso, se dedicó a la práctica de la abogacía y a escribir sus Investigaciones pedagógicas, que publicó en la década del '30. Por estos años, gestó la revista Facundo, a partir de la cual expuso su filosofía política y sus ideas pedagógicas. En esos años de madurez, trazó una obra caracterizada por tres ejes, su oposición a todo pensamiento hegemónico, sea positivista como clerical, una propuesta sobre el concepto de Nación que se aleja del sentido clásico del modelo europeizante y una propuesta pedagógica localista que nomina facúndica. Estas investigaciones fueron de una originalidad de difícil catalogación:

Los nacionalistas no lo admitieron como uno de los suyos en cuanto era uno de los creadores del ideario de la Reforma Universitaria, y reformistas e izquierdistas lo repudiaron por sospechar un contenido "corporativista" en su prédica nacional. (Ferrero, 1988, p. 11)

De 1923 a 1927 realizó un viaje de formación en Europa en donde tomó clases en Marburgo junto a Paul Natorp; se formó en Zurich, Viena y París., Taborda manejaba el idioma alemán y Freud fue leído en su lengua original y también desde los textos de los primeros lectores del psicoanálisis español. Apenas arribó a Córdoba, se abocó a la escritura de sus Investigaciones pedagógicas, que fueron publicadas en el emprendimiento editorial de Martínez Paz, la Revista de la Universidad Nacional de Córdoba (RUNC), en el año 1930. Esta obra de Taborda estuvo redactada en cuatro tomos; en la $R U N C$, sólo se publicó el tomo cuatro que se tituló Bases y proposiciones para un sistema docente (Taborda, 1930). Luego, serían compiladas en 1951 bajo la dirección del Ateneo Filosófico de córdoba y editadas por Assandri. En la publicación de 1930, propuso una serie de articulados que regulaban todo el sistema educativo. ${ }^{13}$ Destinaba, en el Artículo 25,

\footnotetext{
${ }^{13}$ En efecto: Bases y proposiciones para un sistema docente argentino se publicó el año 1930 en la Revista de la Universidad Nacional de Córdoba, o sea, cronológicamente, antes que el tomo primero -editado por esa casa de estudios en 1932- y mucho antes, también, que Taborda elaborase definitivamente los tomos
} 
que el precepto de los colegios nacionales se dictara en el segundo año:

Problemas y direcciones esenciales de la Literatura Argentina. Latín. Teoría de las Ciencias. Historia de la Pedagogía. Psicología. El niño en la Biología y la Etnología. Freudismo. Ejercicios corporales. (Taborda, 1951, p. 242)

Desde la concepción de la Escuela Única, iba a criticar el uso del dispositivo educativo como formador exclusivo de ciudadanos, criticó el positivismo que fundaba una dominación cultural centralista, bonaerense, que sobre todo se plegaba a la cultura francesa. Esa insistente búsqueda de formación del ciudadano había dejado de lado, para Taborda, la formación del hombre. Es evidente aquí la influencia de Ortega, de quien resaltaba su concepción sobre la personalidad y la vitalidad, al mismo tiempo declaraba:

Nunca se encarecerá lo bastante la meditación del ensayo del pensador español, Biología y Pedagogía publicado en el Tomo III de El espectador, el ensayo pedagógico más denso que existe en la literatura castellana. (Taborda, 1951, p. 283)

En el texto de Taborda, la familia e infancia eran objeto de estudio de una pedagogía que buscaba una "rehabilitación del eros", añadiendo: "que todos sepan esto con claridad y justeza" (Taborda, 1951, p. 291). Una concepción holista del hombre que contemplaba cuerpo y alma y proponía una educación de los dos sexos, pues "La escuela única es también sexual",fue una propuesta que se opuso al cientificismo de Bunge e Ingenieros sobre la vida amorosa, al tiempo en que se opuso a la gazmoñería monacal. La educación que propuso esta Escuela tendía a la relevancia del cuerpo y sus manifestaciones:

La danza procede del hontanar del instinto y torna a él, afinándolo. Una escuela norteamericana, la Childrens School, la ensaya: junto con otras manifestaciones artísticas infantiles, aplicando principios freudianos. El sentido del ritmo y actividades como el deporte crean la confianza con el cuerpo y

segundo y tercero, "los cuales han permanecido hasta hoy inéditos" (Taborda, 1951:T. IV, 234). refuerzan la conciencia de sus valores. El cuerpo tiene su idioma y ese idioma está hecho para la relación entre seres humanos. Idioma rico en gestos, actos, movimientos y expresiones, que es, hoy, un monólogo triste y mecanizado. (Taborda, 1951, p. 302)

Si las ideas de Freud estuvieron insertas en su proyecto facúndico fue para comprender la constitución infantil y la importancia de la sexualidad. Las referencias a Freud no eran muy profusas, pero dejaban ver un interés alineado con el vitalismo. Una comprensión del eros infantil y una serie de pautas pedagógicas que indicaban ciertas prácticas sobre el cuerpo. En el fondo, allí se encontraba a la sexualidad infantil como una querella en contra de la moral cristiana y, en su faceta vitalista, una oposición al positivismo, puesto que revelaba la importancia de brindar un espacio que desplegara las particularidades del cuerpo en oposición al ejercicio mecánico de la gimnasia positivista. Una búsqueda que implicara el descubrimiento de las particularidades del cuerpo en su potencia erógena y creativa. Es decir que estas técnicas de tratamiento del cuerpo buscaban una alternativa a esa uniformidad del cuerpo que se presentaba desde las pedagogías positivistas.

\section{La recepción negativa de Freud y el neotomismo cordobés}

En Córdoba, como ya hemos mostrado, el tradicionalismo monacal tuvo un impacto sin comparación en todas las instituciones, sean derivadas del dispositivo médico o de la educación. Una organización, el Círculo de Médicos Católicos, organizó a los egresados de la Facultad de Medicina. En el seno de esta organización, el presbítero Filemón Castellano expuso sus críticas a la obra del vienés.

Su postura respecto del psicoanálisis se hace clara en las tres conferencias que dictó en el marco del "Consorcio de Médicos Católicos de Córdoba" en 1939, publicadas en primera instancia en la Revista de la UNC, con el nombre de "Freud y el psicoanálisis". Breve introducción al psicoanálisis de Freud. Breve exposición del freudismo" (1939-1940) y luego editadas en un pequeño libro llamado "El psicoanálisis de Freud" (1941) por la editorial Difusión. En 1946, Castellano dirigió la tesis doctoral de Cacciaviliani, titulada "Psicoanálisis", en donde se adhirió miméticamente a las tesis del cura cordobés. Además de todo esto, el tribunal de evaluación de la tesis estaba 
compuesto por Héctor Luís Torti, Francisco Torres (Profesor de Psicología, en Filosofía en los años 194244-46) (Piñeda, 2005) y, presumiblemente, Alfredo Fragueiro (Profesor de Historia de la Filosofía) -decimos presumiblemente porque la firma en el acta no es del todo legible-, todos ellos ligados a la corriente neoescolástica en Córdoba.

Las argumentaciones que desarrolló estaban cargadas de una gran ambivalencia en planos diferentes, pasando del elogio de la persona de Freud al repudio total de algunas de las concepciones fundamentales de la teoría psicoanalítica. A partir de "Las conferencias para médicos y público en general hechas por el maestro de Viena en 1916-1917', y reunidas con el título Introduction a la Psychanalyse (Castellano, 1942), fue que Castellano iba a desarrollar el hueso de sus tres conferencias. Esencialmente, se hizo de las ideas de Jacques Maritain, "en las conferencias que diera en la Facultad de Letras de Buenos Aires y cuyo título era Freudismo y Psicoanálisis" (Castellano, 1939-1940, p. 19), quien a su vez retomó a Dalbdiez con su reconocido análisis de la teoría de Freud que la escindía en tres enunciados:1) era un buen método, 2) la filosofía de Freud no era aceptable; 3) la psicología freudiana estaba viciada por un empirismo radical y metafísica aberrante (Castellano, 1942, p. 20). El punto en que el compromiso teórico de la doctrina de Freud no era aceptable fue, evidentemente, el pansexualismo. En Cacciaviliani, hubo un intento de superarlo, proponiendo sintetizar las tesis sobre la dimensión energética de Jung (en el original "Yung" $)^{14}$ y Adler.

Según Filemón, las conclusiones a la que arribaba Freud eran equívocas dadas las condiciones del medio en donde las produjo, la sociedad victoriana, judía en particular:

En el fondo de toda neurosis hay un querer y un no querer, una represión a medias. Eso vale sobre todo para las mujeres judías, más ociosas que sus maridos, más refinadas como mujeres, vidriosas y exacerbadas por el antisemitismo cortesano [...] Por añadidura, sin poderse desinfectar el interior, como los católicos, en ese divino y humanísimo sacramento de la confesión. Así resultó Freud el confidente o confesor laico de las

\footnotetext{
14 "Creemos también que si se une la concepción energética de Yung [sic] con la de Adler, estaríamos tocando casi con las manos la anhelada síntesis, tercero y último término, relativo claro está, dentro del proceso dialéctico Hegeliano" (Cacciaviliani, 1946, p. 65).
}

hebreas vieneses. Ahí nació el freudismo.

(Castellano, 1939 p. 86)

Castellano ubicó a Freud como confesor laico, definiéndolo como alguien que descubrió, nuevamente, la pólvora del sacramento de la confesión, tomando a Janet. ${ }^{15}$ Luego sostuvo que si en cambio el medio de producción de las ideas freudianas hubiese sido una realidad social menos frívola, pues, el psicoanálisis habría arribado a una valorización más acentuada de los instintos de conservación del Yo. ${ }^{16}$

Filemón intentó, en el ámbito del "Consorcio de Médicos Católicos de Córdoba" en 1939, "hablar con justeza" sobre "la fantasía calenturienta" de Freud (Castellano, 1942). Luego las conferencias se publicaron, no sólo en 1939 en la revista de la UNC, en el apartado sobre medicina sino que también, en 1941 se publicaron en formato de libro. Esto es un indicador de la lucha por los espacios de poder. La medicina había estado durante mucho tiempo afectada por el pensamiento religioso. Freud era un discurso y una práctica que introducía postulados que producían una laicización del campo educativo a partir de la medicina. Es comprensible que haya habido una proliferación de discursos en su contra. Como mostramos anteriormente, el psicoanálisis había sido receptado por una corriente progresista identificada con el grupo reformista y, más adelante, con la izquierda cordobesa (Bermann). Si en Buenos Aires se presentaba la posibilidad de que el psicoanálisis fuese adoptado por médicos católicos o que fuera rechazado por el clérigo Castellani, pero sin muchos efectos, en Córdoba la oposición al psicoanálisis provino de ésta vertiente cultural enraizada en las creencias religiosas. En los planteamientos de Filemón Castellano, en Cacciaviliani y en todos los intelectuales alineados con el neotomismo, el psicoanálisis terminó por ser rechazado, trocado por el noble placer eclesiástico de la expiación que se hacía dueña del instrumento que había venido a ser arrebatado de las manos de la iglesia, la palabra. Finalmente, Castellano afirmó:

Todo esto es fantasía calenturienta de un hombre sistemático, que olvidando su prestigio de honesto investigador ha hecho

\footnotetext{
15 "Los sacerdotes han conocido la enfermedad del escrúpulo mucho antes que los médicos y la confesión ordinaria parece haber sido inventada por un alienista de genio que se propusiese curar a obsesionados" Janet, citado por J. De La Vaissiere Psicología Experimental (1924) (Castellano, 1942, p. 81).

16 'Programa de Psicología 1944 y 45 del Instituto de filosofía de la UNC.
} 
literatura; y de esa pobre literatura que se llama pseudo-científica. (1941, p. 82)

En Buenos Aires, tal como plantean Plotkin (2003) y Vezzetti (1996), no se presentaba una polarización tan acentuada que no permitiera la convivencia de la diversidad en términos de compromisos políticos y científicos. Este aspecto, permitió que médicos como Ramón Beltrán, adhirieran al psicoanálisis mientras sostenían una postura de derecha y creencias religiosas; en cambio en Córdoba, en donde el pensamiento cristiano tenía injerencias en todas las facetas de la vida cultural, esto no pudo suceder. Buenos Aires, más permeable al positivismo y al progresismo enmarcado por la cultura francesa, si bien la primera recepción crítica fue alentada por lecturas de segunda mano, en francés y afectada por la profunda influencia de las tesis de Janet, se permitieron algunas concesiones respecto de la obra de Freud.

Si hemos visto a Filemón Castellano expresando sus opiniones en torno a la obra de Freud en el Consorcio de Médicos cristianos, Ramón Brandán, miembro del mencionado órgano y docente de Patología Médica en la Facultad de Medicina (la misma cátedra en la que se desempeñó Jorge Orgaz), terminaba por sancionar, no sólo a la teoría de Freud, sino al ya estudiado fenómeno popular que suscitó su temprana difusión en textos e vulgarización texto El aborto provocado de 1939:

La doctrina Freudiana, falsa en sus generalizaciones psicológicas, encierra una profunda verdad en el terreno de la patología médica y nerviosa y es éste precisamente el aspecto que los freudianos no conocen, porque sólo viven la medicina de escritorio o en la redacción de periódicos, donde han ido convirtiendo el capítulo más noble de la ciencia médica, en capítulos literarios para negocio de librería.". Finalmente terminaba por exponer su compromiso con "....una salud fisiológica, una salud mental y una salud sobrenatural...”. (Brandán, p. 22)

\section{Conclusiones y discusión}

Tal como hemos establecido con anterioridad, nuestro estudio busca desnaturalizar ciertas lecturas que se han establecido en la historiografía del psicoanálisis en Argentina. Pudimos mostrar cómo los trabajos previos generalizan los resultados obtenidos en la recepción de las ideas de Freud en Buenos Aires al introducir un análisis de las condiciones de recepción en Córdoba. Esto nos permite cuestionar estas historias centralizadas y enriquecer el panorama cultural de la historia del psicoanálisis en Argentina. Creemos que este tipo de estudio abre la posibilidad de comprender los procesos de recepción de las ideas teniendo en cuenta las particularidades locales en términos multicéntricos, que no pueden ser generalizadas. A su vez nos permite introducir el problema de las tensiones interior/puerto en la consideración de la recepción de las ideas psicológicas en Argentina. De esta manera, se introduce una variable que no había sido tenida en cuenta hasta el momento por otros estudios previos.

En este sentido, si bien acordamos con el planteo de Vezzetti, cuyas investigaciones prueban que no hubo nada parecido a un sistema que organice la recepción de las ideas de Freud, sí podemos decir que el rechazo total de la figura y obras de Freud en Córdoba, debido al gran impacto del pensamiento religioso, fue una característica local destacable, que se distancia de las condiciones de recepción bonaerenses. En ese punto, si Vezzetti ha podido afirmar que en Buenos Aires la oposición estuvo muy limitada al padre Castellani y la revista Criterio, en Córdoba encontró apoyo en la universidad, en el seminario, en el Consorcio de Médicos Católicos y en las instituciones fuertemente afectadas por la presencia religiosa. En este sentido, las investigaciones que realizó Vezzetti sostenían que:

... En efecto, la oposición entre el freudismo y el "familiarismo" propio de la tradición católica arroja una luz importante sobre las conocidas dificultades de implantación del psicoanálisis en países con tradición católica arraigada, como Francia e Italia. Y en todo caso, viene a mostrar el papel cumplido por esa tradición laica y progresista que se construyó en zonas de la cultura de izquierda desde José Ingenieros a los libros de Claridad. Como se vio, Ingenieros casi no habló de Freud, y sin embargo contribuyó a crear las condiciones de una recepción de Freud, en ese terreno resbaladizo constituido por las cuestiones del amor sexual, separado del sentido común eugenésico. Las consecuencias de su obra pueden ser vistas como un acondicionamiento del campo, como la operación que despeja propiamente ciertas tradiciones de lectura para hacer posible que 
otras emerjan. En esa dirección las iniciativas de la editorial Claridad no hacen sino continuar la instauración de una tradición de recepción: laica y reformista, naturalista (opuesta por lo tanto a líneas afines a la sensibilidad literaria fantástica tanto como a las inclinaciones al misticismo que alientan una obra como la de Jung) y legitimadora del amor sexual como un territorio abierto a la búsqueda de la felicidad individual.

Desde esas condiciones, el cuestionamiento católico quedó aislado, recluido en revistas como Criterio y en autores como el padre Castellani, sin mayor capacidad de penetrar la trama de la cultura intelectual ni mucho menos las expresiones las expresiones crecientes que en la cultura popular impulsaron una recepción "plebeya" de Freud. Al mismo tiempo, el marco de esa recepción fue liberal progresista, positivista y naturalista en ciertos casos, pero abierto a una dimensión universalista: no hubo nada parecido a una oposición desde el antisemitismo o resistencias afincadas en el nacionalismo cultural. Aun un nacionalista, profesor del Colegio Militar, amigo de Uriburu y admirador del ejército, como Juan R. Beltrán, estuvo exento de ello, aunque se propuso hacer compatible a Freud con la religión, ya que su inspirador era el pastor protestante y liberal Oskar Pfister. $Y$ si la influencia francesa fue importante en la recepción psiquiátrica del freudismo, una diferencia central radicó, en la Argentina, en la presencia nula del prejuicio nacionalista antisemita que dominó la escena parisina. $(1996 \text { d, p. 127) })^{17}$

Plotkin (2003) sostuvo también los mismos resultados en su "Freud en las Pampas." Sin embargo creemos que estas conclusiones no pueden ser generalizadas a lo ocurrido en Córdoba. Por ello, veremos una serie de lectores de la obra de Freud que respondían a esas condiciones locales de recepción, en las que la intelectualidad religiosa mantuvo un tajante rechazo de la obra de Freud, al tiempo que prefirió algunas lecturas ligadas a las figuras de Adler y Jung. El medio cultural cordobés, afirmamos una vez más, contenía particularidades que no permiten que las conclusiones

\footnotetext{
${ }^{17}$ La cursiva me pertenece.
}

que se desprenden de los estudios históricos realizados en Buenos Aires, Rosario y La Plata, puedan generalizarse. Si sintetizamos los resultados obtenidos por los estudios realizados en estas provincias, diremos que el psicoanálisis fue receptado en un espacio cultural particular que implicaba: 1) predominio de una recepción del liberal y progresista, en muchos casos ligada al positivismo y el naturalismo; 2) una recepción con el tamiz de la crítica francesa; 3) la inexistencia de una crítica antisemita de la intelectualidad cristiana.

En éste trabajo hemos intentado mostrar que en Córdoba sobrevivió con particular vigor: 1) el pensamiento católico con visos claros de antisemitismo; 2) la recepción de la obra de Freud no fue, al igual que en Buenos Aires, mayormente realizada por una corriente positivista y naturalista, y 3) la existencia de un conjunto de intelectuales que, afectados por la cultura hispánica, el vitalismo de Ortega y Gasset y Eugenio D'Ors en particular, tomaron a Freud como parte de una crítica a esas dos formas de hegemonía. Por esta razón, se opusieron tanto a la hegemonía que planteaba el positivismo como la que planteaba la intelectualidad religiosa que buscaba restituir el pensamiento neo-tomista. En este sentido, la recepción fue comparativamente tardía a lo ocurrido en Buenos Aires, puesto que la lectura de la obra de Freud se hizo más sistemática a finales de la década del veinte.

A su vez, hemos podido relacionar esta presencia de las filosofías vitalistas españolas a un compromiso con la cultura y lenguas españolas más amplio. Gran parte de los intelectuales influenciados por la cultura hispánica sostuvieron una postura crítica respecto del centralismo bonaerense. Su misma adherencia a la cultura española se opuso a la proliferación de la cultura francesa en Buenos Aires. Estas preferencias culturales se tornan comprensibles si tomamos en cuenta el problema de la dicotomía interior/puerto y observamos la reticencia ante la estrategia de importación cultural de cuño sarmientino.

\section{Referencias}

Altamirano, C. (2005). Para un programa de historia intelectual y otros ensayos. Buenos Aires: Siglo XXI Editores.

Argañaraz, J. de la C. (2007). El freudismo reformista,1926-1976: En la Literatura y la Medicina, la Política y la Psicología. Córdoba: Brujas.

Asenjo, C. \& Gabaráin, I. (2002). Viaje a la Argentina, 1916. Revista de estudios Orteguianos, 4, 29-86. Recuperado de http://www. ortegaygasset.edu/publicaciones/revista-de-estudios-orteguianos/ numero-4-mayo-de-2002 
Barrancos de Bermann, L. (1931). La reforma educacional en Austria, Revista de la Universidad Nacional de Córdoba, 18(3-4), 103117. Recuperado de http://revistas.unc.edu.ar/index.php/REUNC/ article/view/6398/7479

Bermann, G. (1920). El Determinismo en la Ciencia y en la Vida. Nosotros, 133.

Bermann, G. (1921). La filosofía del señor Eugenio D’Ors. De los límites de la filosofía y la literatura, Nosotros, 147(144), 477.

Bermann, G. (1925). Psicopatogenia de las toxicomanías, Revista de la Universidad Nacional de Córdoba, 12(4-6), 128-161. Recuperado de http://revistas.unc.edu.ar/index.php/REUNC/article/ view/6416/7497

Bermann, G. (1926) Toxicomanías. Buenos Aires: El Ateneo.

Bermann, G. (1934). Psicogénesis de la locura moral. Buenos Aires: El Ateneo.

Bermann, G. (1936a). Patogenia de la neurosis obsesiva. Psicoterapia, 2(2-4), 13-29.

Bermann, G. (1936b). Sobre la resistencia en psiconeurosis. Los neurópatas que 'no quieren' curar. Psicoterapia, 1(1-4), 46-55.

Bischoff, E. (1977). Historia de Córdoba. Cuatro Siglos. Córdoba: Plus Ultra.

Brandán, R. A. (1939). El aborto provocado. Buenos Aires: Talleres Gráficos San Pablo.

Brock, A., Louw, J. \& Van Hoorn, W. (2005). Rediscovering the history of psychology. Essays inspired by the work of Kurt Danziger. New York: Kluwer Academic Publishers.

Cacciaviliani, E. C. (1946). Psicoanálisis (Tesis doctoral). Córdoba: Facultad de Filosofía y Letras.

Campomar, M. (2003). Nuevas y viejas generaciones Argentinas. Entre el positivismo de José Ingenieros, el vitalismo de Ortega y Gasset y la renovación novecentista de Eugenio D'Ors. Revista de Estudios Orteguianos, 7, 195-246.

Castellano, F. (1939-1940). Freud y el psicoanálisis. Breve introducción al psicoanálisis de Freud. Breve exposición del Freudismo, Revista de la Universidad Nacional de Córdoba 27, 156-187.

Castellano, F. (1942). El psicoanálisis de Freud. Córdoba: Difusión.

Colodrero Lazcano, O. (1908). Teoría de la culpa en materia penal. (Tesis de derecho). Universidad Nacional de Córdoba, Córdoba.

Dagfal, A. (2004). Para una "estética de la recepción de las ideas psicológicas". Frenia, Revista de Historia de la Psiquiatría, 4(2), 7-16. Recuperado de http://www.revistaaen.es/index.php/frenia/ article/view/16407/16253

Danziger, K. (1994). Does the history of psychology have a future? Theory \& Psychology, 4(4), 477.

Danziger, K. (2010). Problematic Encounter: Talks on Psychology and History. Recuperado de http://www.kurtdanziger.com/title\%20page.htm

Ferrari, F. \& Orgaz, S. (Noviembre y Diciembre, 2007). Estudio exploratorio sobre los vínculos entre intelectuales españoles y los primeros lectores de Freud en Córdoba (1916-1937). Actas del VIII Encuentro Argentino de Historia de la Psiquiatría, la Psicología y el Psicoanálisis. Universidad Nacional de Mar del Plata, Argentina.

Ferrari, F., Argañaraz, J. \& Argañaraz, M. L. (Noviembre, 2004). Primeros contactos de Gregorio Bermann con el Psicoanálisis (1913-1919). XV Jornadas de Epistemología e Historia de la Ciencia. Universidad Nacional de Córdoba, Argentina.

Ferrari, F. (2012). Entre el dispositivo psiquiátrico y la disciplina monacal: una historia genealógica de las primeras lecturas de la psicopatología freudiana en Córdoba (1758-1930) (Tesis doctoral inédita). Universidad Nacional de Córdoba, Argentina.

Ferrero, R. A. (1988). Saúl Taborda. Córdoba: Alción.

Ferrero, R. A. (1994). La concepción histórica de Alfredo Terzaga. Córdoba: Alción.

Ferrero, R. A. (1999). Breve historia de Córdoba. Córdoba: Alción.
Filloy, J. (1934). Op Oloop. Buenos Aires: Ferrari Hermanos. Filloy, J. (1968/1931). Estáfen!, Buenos Aires: Paidós.

Filloy, J. (2007/1930). Periplo. Buenos Aires: El cuenco de plata.

Gentile, A. (2000). Ensayos históricos sobre psicoanálisis y psicología en la Argentina 1927-1960. Rosario: Fundación Ross.

Glick, T. F. (1982). The Naked Science: Psychoanalysis in Spain, 1914-1948, Comparative Studies in Society and History 24(4), 533-571. Recuperado de http:// links.jstor.org/sici?sici=0010-4175\%28198210\%292 4\%3A4\%3C533\%3ATNSPIS\%3E2.0.CO\%3B2-J

Gonzáles, N. (1890) La escuela positiva (Tesis de derecho). Universidad Nacional de Córdoba, Córdoba.

Guerrero, J. (Octubre, 2008). Psychopathia Sexualis y Freudismo en Caterva de Juan Filloy. Actas del IX Encuentro Argentino de Historia de la Psiquiatría, la Psicología y el Psicoanálisis. Universidad de Buenos Aires, Buenos Aires.

Guerrero, J. M. \& Ferrari, F. (Noviembre, 2006). Curiosas relaciones entre la obra literaria de Roberto Arlt y Juan Filloy. Actas del VII Encuentro Argentino de Historia de la Psiquiatría, la Psicología y el Psicoanálisis. Universidad Nacional de La Plata, Argentina.

Iser, W. (1972). The Reading Process: a phenomenological approach. New Literary History, 3(2), 279-299. doi:10.2307/468316

Jauss, H. R. (1981). Estética de la recepción y comunicación literaria. Punto de Vista, 12, 34-40.

Jauss, H. R. (1990). The theory of reception: a Restrospective of its unrecognized prehistory. En P. Collier \& H. Geyer-Ryan (Eds.), Literary Theory Today (pp. 53-73). New York: Cornell University Press.

Klappenbach, H. (1999). La recepción orteguiana, Alberini y la renovación de la psicología argentina a partir de los veinte. Revista de Historia de la Psicología, 20(1), 87-95. Recuperado de http:// www.revistahistoriapsicologia.es/app/download/5971675211/07 .+KLAPPENBACH.pdf? $\mathrm{t}=1392120940$

Klappenbach, H. (2006). Periodización de la psicología en Argentina. Revista de Historia de la Psicología, 27(1), 109-164. Recuperado de http://www.revistahistoriapsicologia.es/app/download/584201 3511/5+KLAPPENBACH.pdf?t=1363003137

Klappenbach, H. (2014). Acerca de la Metodología de investigación en la Historia de la Psicología. Psykhe, 23(1), 1-12. doi:10.7764/ psykhe.23.1.584

Kohan, N. (1999). Deodoro Roca, el hereje. Buenos Aires: Biblos.

Liqueno, J. M. (1919). Compendio de Psicología Contemporánea. Córdoba: Bautista Cubas.

Montero, I. \& León, O. G. (2005). Sistema de clasificación del método en los informes de investigación en psicología. Revista Internacional de Psicología Clínica y de la Salud, 5(1), 115-127. Recuperado de http://www.aepc.es/ijchp/articulos. php?coid=Espa $\%$ F1ol \&id= 136

Nores, N. M. (1904). Factores del delito (Tesis de derecho). Universidad Nacional de Córdoba, Argentina.

Orgaz, J. (1934). La vida como enfermedad. Buenos Aires: Araujo Hermanos.

Orgaz, J. (1959). Profesión y vida. Buenos Aires: Morena.

Orgaz, J. (1966a). En torno al escritor. Imaginación y fantasía Universidad Nacional de Córdoba: Dirección General de Publicaciones.

Orgaz, J. (1966b). La clínica y el médico. Buenos Aires: Aguilar.

Orgaz, J. (1970). Unamuno y sus espejos. Córdoba: Librería Científica Olocco.

Orgaz, J. (1977). El humanismo en la formación del médico. Buenos Aires: Losada.

Orgaz, J. (1978). Memoria de ciudad Chica. Córdoba: Olocco.

Ortega \& Gasset, J. (1920). Pedagogía de las secreciones internas. Revista de la Universidad Nacional de Córdoba, 7(5-6), 
106-120. Recuperado de http://revistas.unc.edu.ar/index.php/ REUNC/article/view/5810/6695

Oviedo, G. (2008). Apostillas a la historia del voseo argentino (18282006). En H. González (Comp.), Beligerancia de los idiomas. Un siglo de discusión sobre la lengua latinoamericana (pp. 74-184). Buenos Aires: Colihue Universidad.

Piñeda, M. A. (2004). Comienzos de la profesionalización de la psicología, la Universidad Nacional de Córdoba y el movimiento neoescolástico, Memorandum, 7, 165-188. Recuperado de http:// www.fafich.ufmg.br/ memorandum/artigos07/pineda01.htm

Piñeda, M. A. (2005). El impacto de la Psicología Neoescolástica Experimental en Argentina, a través de libros de psicología de circulación en el país: 1935-1965, Memorandum, 8, 88-105. Recuperado de http://www.fafich.ufmg.br/ memorandum/artigos08/ pineda02.htm

Piñeda, M. A. (2007). La creación de la carrera de psicología en universidades católicas Argentinas, Memorandum, 12, 6-28. Recuperado de http://www.fafich.ufmg.br/ memorandum/a12/ pineda03.htm

Plotkin, M. B. (2003). Freud en las pampas: Orígenes y desarrollo de una cultura psicoanalítica en la Argentina (1910-1983). Buenos Aires: Sudamericana.

Prado, H. G. (2008). Rafael Altamira en América, 1909-1910: Historia e Historiografía del proyecto americanista de la Universidad de Oviedo. Madrid: Consejo Superior de Investigaciones Científicas.

Prieto, M. (2006). Breve historia de la literatura Argentina. Buenos Aires: Taurus.

Ricoeur, P. (2004). La memoria, la historia, el olvido. Buenos Aires, Argentina: Fondo de Cultura Económica.

Roca, D. (1916). De la fabla caballeresca. Revista de La Universidad Nacional de Córdoba, 3(3), 50-59. Recuperado de http://revistas. unc.edu.ar/index.php/REUNC/article/view/5641/6535
Sanguinetti, H. (2003). Trayectoria de una flecha. Las obras y los días de Deodoro Roca. Buenos Aires: Librería Histórica.

Soria, B. (1915). Sueño y ensueño en la segunda infancia. Un capítulo de psico-patología infantil. Revista de la Universidad Nacional de Córdoba, 2(6), 400-415. Recuperado de http://revistas.unc.edu. ar/index.php/REUNC/article/view/3375/6185

Stucchi, A. (1916). Manual de medicina legal. Dispuesto con arreglo a la legislación argentina y adaptado a los programas vigentes de las Facultades de Medicina de Buenos Aires y Córdoba. Córdoba: La semana médica.

Taborda, S. (1922). Las líneas pedagógicas de Eugenio D’Ors, Boletín de la Facultad de Derecho de la Universidad Nacional de Córdoba, 1(2), 25.

Taborda, S. (1930). Investigaciones pedagógicas (I). Revista de La Universidad Nacional de Córdoba, 3-4(17), 65-109. Recuperado de http://revistas.unc.edu.ar/index.php/REUNC/article/ view/7288/8378

Taborda, S. (1941). La crisis espiritual y el ideario argentino. Santa Fe: Universidad del Litoral Instituto Social.

Taborda, S. (1959). La psicología y la pedagogía. Córdoba: Universidad Nacional de Córdoba.

Taborda, S. (2006). Reflexiones sobre el ideal político de América Latina. Buenos Aires: Grupo Editor Universitario.

Taborda, S. (1951). Investigaciones pedagógicas. Córdoba: Assandri. Vezzetti, H. (1985). La locura en la Argentina. Buenos Aires: Paidós.

Vezzetti, H. (1996a). Freud en Buenos Aires. Bernal: Universidad Nacional de Quilmes.

Vezzetti, H. (1996b). Aventuras de Freud en el país de los argentinos. Buenos Aires: Paidós.

Vezzetti, H. (1997). Historia del freudismo e historia de la sexualidad: el género sexológico en Buenos Aires en los treinta. Prismas. Revista de historia intelectual, 1, 211-218. 